\title{
Psychological Assistant Bot Using Artificial Intelligence to Improve Individuals' Mental Health
}

\author{
Shomoita Jahid Mitin \\ Department of Computer Science and Engineering, Jahangirnagar University, Savar, Dhaka, Bangladesh \\ Corresponding Author: shomoita.mitin.aub@gmail.com
}

Abstract- The ignorance of mental health has caused many lives. But there is no awareness among the people because most of the people of our country do not treat mental health issues as equally they treat the physical issues and disagree to consult with any psychologist or spend money for psychological issues. The proposed idea is to create a psychological assistant bot using Artificial Intelligence based on supervised learning method that can diagnose the disease and provide basic instructions before consulting a doctor. To reduce the healthcare costs and improve accessibility to psychological knowledge the Psychological Assistant Bot (PAB) is built. I have tried to build a prototype of a system that will take text input and give an output after processing. Chabot is computer programs that mimic human conversation to interact with users through a variety of messaging channels. Chabot have also been employed for research and clinical support in every sector - domain. In the field of psychology, chatbots have been applied to informative research where survey or interview data collection are substituted with chatbots that can interact with the subjects in web messaging apps in a psychological setting. This paper examines the design and development of a Chabot for a psychology research study. The stakeholders, functionality, perspectives and technical challenges are presented and discussed. I apply a quality of experience framework to explore the factors that impact stakeholders and influence design priories. 


\section{INTRODUCTION}

A conversational chatbot is a computer program that tries to mimic a conversation with a real person. State-of-theart chatbots believe underlying AI (AI) and tongue Processing (NLP) technologies to deliver a natural conversation experience. In general, chatbots can be classified into two categories: task-oriented and conversational chatbots. Task-oriented chatbots operate within the boundaries of a pre-defined set of rules and are limited in their scope of activity. With basic pattern matching these are as simple as commonly asked question (FAQ) chatbots with a limited number of responses. Conversational chatbots believe NLP to extract information from the users' text then react with a highly matched response. Many also use AI to improve the accuracy of the response over time, like virtual agent chatbots. From a user end perspective, a general conversational chatbot will naturally handle various scenarios are desirable. In practice, however, chatbots are constrained in their design to specific purposes. Our chatbot interacts with the users about their psychological obstructions remedially solution as we know Psychology is the science of behavior and mind.

Study of unconscious and conscious behavior we are commonly calling it psychology, it also includes peoples thought and feelings. It is an innumerable scope of academic study and research. Psychologists wants to get the knowledge of the brain's important functionalities, and all people the non-constant of phenomena linked to those important properties, start working this way to the bigger neuroscientific group of researchers. After researching different cases some general principles can be stablished, as a science it basically targets to understand group of people or some individuals. [1][2] [15]

In this field, knowledgeable practitioner or researcher is known as a psychologist and should be classified as a social, behavioral, or scientific. Main target of the psychologists is to understand the roles of mental functions during social and personal behavior, they usually plan to do it during the exploring the process of biological and psychological states that marks the cognitional behaviors and functions. They actually explore way of behavior thus includes personality, intelligence, mental, processes, cognition, including perception, attention, emotion, subjective, motivation, experiences and brain functioning. This expands the interaction among people, such as interpersonal relationships that may include psychological liveliness, family and social, resilience, and other areas. Psychologists from different orientations also rack of the unconscious [3] they apply experimental methods to guess etiological and correlational relationships among different psychosocial variables. In addition, or con, to employing empirical and deductive methods, some specialist clinical or counseling based psychologists actually times depend on symbolic interpretation and other motivational methods. When knowledge of psychology is generally applied to any assessment for the treatment of psychological problems, it is also drives toward problem solving and understanding different type of acts. By many accounts psychology ultimately aims to profit society. [5][6] The bulk of psychologists are involved in some quite therapeutic role, practicing in clinical, counseling, or school settings. Many people do research on a good range of topics adjacent to mental processes and behavior, and generally psychology departments of any university or teach in other academic methods (e.g., medical schools, hospitals). Some people are employed in different industrial or in any commercial settings, or in other different sectors [7] like personal development like health, sports and the media, also as in other aspects of law and other forensic inquiry.

\section{A. Motivation}

As discussed earlier, chatbots can generally be classed as task-oriented or conversational. However, hybrid chatbots such it's task-oriented with some chit-chat conversational capabilities also can be created to satisfy a special purpose. We can use chatbots for psychological purposes such as for FAQs (Frequently Asked Questions). It is required that Chatbot for healthcare needs more free discussion within guidelines for an empathy-based user QoE (Quality of Experience). This research focuses on the design challenges faced while developing a chatbot for mental healthcare purposes. The use case was to design and implement an intervention Chatbot for psychological studies, named Psyicbot (Psychological Assistant Bot). Psyicbot is an intervention informed by Relational Frame Theory 
which seeks to reduce instances of problematic rule-following. Specifically, Psyicbot targets generalized pliancy wherein people adhere to rules just because they believe they should. Through conversing with Psyicbot, users examine why they follow their rules and whether or not these rules are useful for them. This paper is motivated by our need to examine the design factors in developing a psychological assistant chatbot that follows a certain conversational intervention dialogue.

\section{B. Objectives}

Main objective of this project is to develop a chatbot where a chit-chat conversation is made with empathy-based user to help them by giving a mental support in their unstable moments on the base of their syndrome. Persons who are in such a situation where they can't understand what should they do, with whom they can share their feeling in that case our Psyicbot can predict their cases and refer them a psychiatric or an effective way that help them.

Psyicbot is an Artificial Intelligence (AI) based software that can be demonstrated as messaging applications, web applications or mobile applications that make it more user friendly. 


\section{PSyChOLOGICAL ASPECTS IN BANGLADESH}

\section{A. Major issues regarding Psychology}

In a developing country like Bangladesh, mental health is ignored. It does not get as much as priority physical health issues get. But the ignorance and denial could not stop suicides. People committing suicide or suffering from mental health issues cannot open up to others and don't get enough support or medical assistance they required. Mental health issues can be cured and proper assurance can reduce suicidal tendency but most people don't want to spend money on psychologists.

\section{B. Psychiatric Disorders and effect of mentionable Psychiatric Disorders in Suicide}

Psychological disorder or mental illness is the reason at the time of suicide $27 \%$ to more than $90 \%$ of the time.[21][20][23][22] Among those who have been hospitalized for suicidal behavior, for them risk percentage of suiciding is 8.6\%.[22][24] Comparatively, non-suicidal people hospitalized for affective disorders have a 4\% lifetime risk of suicide.[63] Half of all people who die by suicide may have major depressive disorder; having this or one of the other mood disorders such as bipolar disorder increases the risk of suicide 20-fold.[25] Other conditions such as schizophrenia (14\%), personality disorders(PD) (8\%),[26][27] OCD(obsessive compulsive disorder),[28] and PSO(posttraumatic stress disorder). [21] Those with autism spectrum disorders also attempt and consider suicide more frequently. [29]

Most people who complete suicide could be diagnosed with a personality disorder as well as borderline personality disorder being the most common .[30] About 5\% of people with schizophrenia die of suicide.[31] Eating disorders are another high risk condition.[32] Almost 80\% of completed suicides, the individual has seen a physician within the year before their death,[33] including 45\% within the prior month.[34] Approximately 25-40\% of those who completed suicide had contact with mental health services in the prior year.[21][33] Antidepressants of the SSRI class appear to increase the frequency of suicide among children but do not change the risk among adults.[35] An unwillingness to get help for mental health problems also increases the risk.[36] But the most mentionable Psychiatric disorders which cause suicide are depression, mental illness, criminality, substance abuse and impulsivity. 


\section{Mentionable Psychriatic Disorders which} cause Suicide

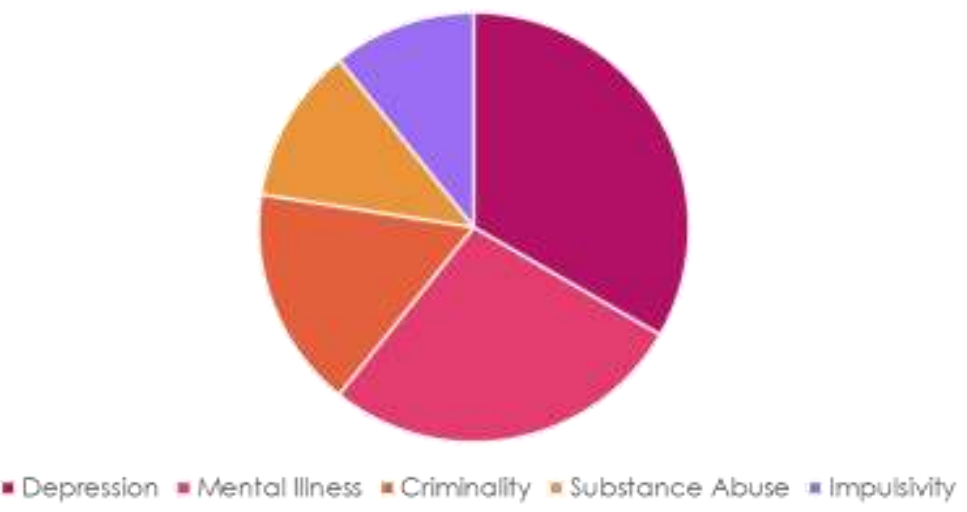

Figure 1: Pie-chart representation of mentionable Psychological disorders and their effects in suicide.

\section{Risk Factors}

So many Factors like mental disorders, drug misuse, psychological states, cultural, family and social situations, genetics, and experiences of trauma or loss can affect the risk of suicide. ${ }^{[38][39][37]}$ Mental disorders and substance misuse frequently co-exist. ${ }^{[40]}$ Other risk factors include having previously attempted suicide, ${ }^{[20]}$ the ready availability of a means to take one's life, a family history of suicide, or the presence of traumatic brain injury. ${ }^{[41]}$ For example, suicide rates have been found to be greater in households with firearms than those without them. ${ }^{[42]}$ Suicidal thoughts can be triggered by socio-economic problems. Suicide might be rarer in societies with high social cohesion and moral objections against suicide. ${ }^{[46]}$ About $15-40 \%$ of people leave a suicide note. ${ }^{[45]}$ War veterans have a higher risk of suicide due in part to higher rates of mental illness, such as post-traumatic stress disorder, and physical health problems related to war. ${ }^{[47]}$ Genetics appears to account for between $38 \%$ and $55 \%$ of suicidal behaviors. ${ }^{[48]}$ Suicides may also occur as a local cluster of cases. ${ }^{[49]}$ The risk factors that lead to thinking about suicide and risk factors that lead to suicide attempts are not often distinguished by most research. ${ }^{[50][51]}$ Risks for suicide attempt rather than just thoughts of suicide include a high pain tolerance and a reduced fear of death. ${ }^{[52]}$

\section{Statistics}

Approximately 19,697 people committed suicide in Bangladesh in 2011 based on a report of the World Health Organization, According to Police Headquarters 11,095 people committed suicide in Bangladesh in $2017^{[2]}$. Around 6,500,000 people of Bangladesh are prone to suicide according to a report by SSMCH published in 2010. The ratio implies that 128.08 people per 100,000 commit suicide in Bangladesh every year. The sixmember team led by Dr. AHM Feroz and the survey was conducted by DR. Nurul Islam. But this was noted that the above rate was assumed only based on survey conducted in one union which does not reflect the total suicide rate, total suicide rate per year in this whole country is far less than what was mentioned in the report in 
the last couple of years. ${ }^{[3]}$ The Daily Star once published a report that mentions from 2002 to 2009, 73,389 people committed suicide in Bangladesh.

\section{E. Case Studies}

- MP's son commits suicide in Khulna (Dhaka Tribune, Thursday, Jan 22, 2020): Avijit Chandra Chanda, panel chairman of Khulna District Council, died while being on a supervision of medical specialists at a Dhaka hospital Wednesday night, said Bishwajit Chandra Chanda, brother of Avijit. He was the youngest son of Khulna 5 MP and former minister Narayan Chandra Chanda. He tried to suicide by ingesting Harpic. He was initially admitted to Khulna Medical College and Hospital $(\mathrm{KMCH})$ on that exact day. Later, he was flown to Dhaka by air ambulance as his condition deteriorated further. ${ }^{[16]}$

- Boy commits suicide after not getting a mobile in Kurigram (Dhaka Tribune, Sunday, Jan 19, 2020): The deceased was a student of Gorok Mandal Govt. School. A student from class three has committed suicide in Kurigram because his parents could not buy him a mobile phone. The incident took place at the Fulbari upazila on Sunday evening. His name was Apon Mia, he was the only son of Ainul Islam. Apon studied in Gorok Mandal Govt. School. From their village, the member of UP Anwar Hossain quoting the deceased's family members said: - A week back Apon wanted a mobile phone, which his father was unwilling to buy because of his son was a small kid, and also because he did not have enough money to buy it for financial reasons. Though the father promised the boy that he would buy him one. As it was taking a lot of time. The boy became sad and decided to commit suicide, Anwar also said.

- Schoolgirls commit suicide over JSC result (Dhaka Tribune, Thursday, Dec 31, 2019): Shahida Akhtar, 14, an examinee from Barisal was upset because she could not do well in the J.S.C. examination and decided to hang herself from the ceiling of her bedroom after coming back home, her family said. She was declared dead when brought into the Hospital, said Kawnia police OC Azizul Karim. After being asked about the incident, Mahbuba Hossain, headmaster of her School, said, she expected to score a GPA-5 (Grade Point Average) at the JSC examinations, but she got GPA-4 instead, which may have influenced her to take her life." On each year so many students commit suicide over their poor result in the different board exams in our country.

- Policeman Killed himself by his own rifle (Daily Jugantar, Thursday, Jan 23, 2020): One of the Police member committed suicide by shot himself lf by his own rifle. Shah Md. Abdul Kuddus (31) 
was appointed as a Nayek at Mirpur - 14 police lines. His native area is Rosulpur, Hobiganj, Sylhet. Fathers name Shah Md. Abdul Wahab. Reason of suicide was not clear at primary glance. Operation in Charge of Kafrul Police station confirmed it to Jugantar. He said, kuddus killed himself by his own rifle in Thursday dawn. Police are investigating to find out the reason of his suicide. ${ }^{[19]}$

Notion: These suicides could have been stopped by proper counselling and assistance.

\section{F. Common Methods of Suicide}

The most common method of suicide in Bangladesh is hanging. The reason is that there is no cost involvement in this method other than ligature material, i.e., a rope, and thus that is why it is the preferred method for suicide. Swallowing poison or medicine is another common method in Bangladesh to commit suicide. Other methods to commit suicide, such as by an overdose of barbiturate tablets are followed by the urban people. 


\section{DIAGNOSIS PROCESSES OF PSYCHIATRIC DISORDERS AND ROLE OF PSYCHOLOGICAL ASSISTANT BOT ON DIAGNOSIS}

\section{A. Diagnosis Processes of Psychiatric disorders}

Psychiatric disorders cannot be cured properly but proper treatment can make the situation better and Psychiatric patients can be under control. But these treatments have to be proper and must follow three valid processes of diagnosis. The three diagnosis processes are:

- Physical Conditions Inspections: In this diagnosis process, Psychiatric Therapists will rule out the Physical Conditions that might be the reason of the Psychiatric Disorders. For different disorders, different Physical symptoms can be seen and based on the Physical Conditions, Psychological Therapist arranges the treatment. It differs from symptoms to symptoms even can vary for patients to patients.

- Diagnostic Tests: For this process, diagnostic equipment is required. Different equipment performs different types of tests. For example, alcohol screening devices can measure alcohol in bodily fluids which can be a diagnosis process for Psychiatric Disorder Substance Abuse.

- Psychological Assessments: In this process methods like talk therapy is used. The Psychological Therapist would try to understand the condition of the disorder by talking with the patient about his feelings, thoughts, symptoms and behavior patterns.

Not all Psychiatric Disorders require all of these processes. It depends on the type of disorder. Some may require all diagnosis processes for better treatment. Some may require any one of the processes at once. A Venn's Diagram is given below to show the diagnosis processes requirements. If we assume, A, B, C, D, E, F and G are different types of disorders that require different diagnosis process/s. For type A's diagnosis, only Physical Condition Inspection process is required. For type B's diagnosis, only diagnostic Tests Process is required. And for type C's diagnosis, only Psychological Assessments process is required. For type D, E and F two merged processes would be required. And for type $\mathrm{G}$ all diagnosis processes would be required.

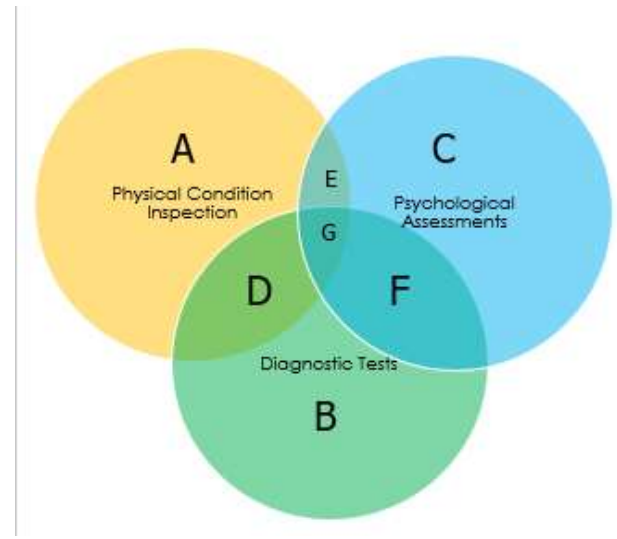

Figure 2: Venn's diagram to represent Diagnosis Processes. 


\section{B. Role of Psychological Assistant Bot on Diagnosis}

PAB (Psychological Assistant Bot) is based on Psychological Assessment Diagnosis Process. Since it is web based application, it cannot inspect user's physical condition as well as it cannot be merged with diagnostic test process. So from the given Venn's Diagram, we can say that only the types of psychiatric disorders those are from either $\mathrm{C}, \mathrm{E}, \mathrm{F}$ and $\mathrm{G}$ can be treated with PAB where $\mathrm{C}$ type disorders can fully depend on PAB treatment and for $\mathrm{E}, \mathrm{F}$ and $\mathrm{G}$ type disorders, patients can partially depend on PAB.

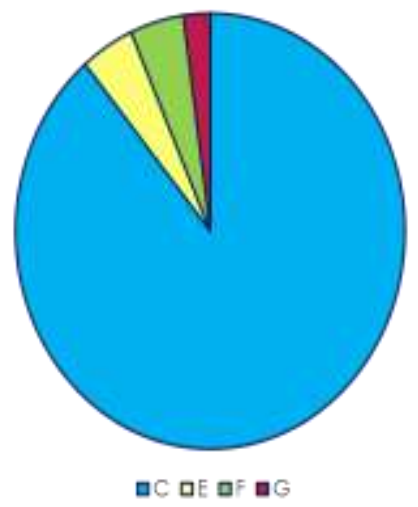

Figure 3: Role of PAB on types of different Psychological Disorders.

\section{Psychological disorder prevention methods}

There are different types of reason for a person having suicide. But all this reasons can be put under one category and that is " Feelings ". Feelings are such a thing that can't be controlled by a person rather, feelings control a person. Most of the suicide happened just because only one reason that is they couldn't share their feelings. There was a battle between their positive and negative mind. Adverse situation more precisely negative feelings gave a booster to the negative mind and at the end of the battle negative mind wins and we lost a beautiful soul. To prevent suicide, we need a powerful booster for positive mind. And that booster is a " new friend ". With a friend we can share our feelings, whenever negative feelings having an approach to give a booster to the negative mind, by sharing our feelings to our friend gives a positive booster which is a best solution to prevent suicide. Some other things also can help to prevent suicide like travel in a new place especially in nature. Travelling gives us a space to find that how much precious our lives are! Gentle wind and murmuring bees make our mind fresh with full of positive energy. Another way of preventing suicide is to do that things what you love to do like art, painting, dance, sing and so on that keeps your mind busy not to recall the memory that you want to forget. Meditation is the supreme way to make unstable mind stable, removing harmful tendency and counselling also help to prevent suicide. Sometimes we need someone to teach us the way to find out the positivity in the negative situation. Counselling a depressed person not only decrease the chances of having suicide but also teach how to enjoy life with positive vibes 


\section{ARTIFICIAL INTELLIGENCE AND ITS AsPeCtS}

A. Artificial Intelligence

Artificial Intelligence is based on how any device perceives its Environment and takes actions based on the perceived data to achieve the result successfully. It is the study of intelligent agents. We use the term "artificial intelligence" if a machine mimics "cognitive" functions that humans associate with other human minds, such as "learning" and "problem solving. Artificial Intelligence gives the supreme power to mimic the human way of thinking and behaving to a computer. ${ }^{[53]}$

B. Self-Assessments

An assistant bot is a software that assists human and allows to initiate a conversation between the user and the system. This is an Artificial Intelligence (AI) based software that can be demonstrated as messaging applications, web applications or mobile applications. A bot represents a question answering system that uses Natural Language Processing (NLP). Formulating responses to questions in natural language. Bots are making a mark in the field of Medicine and provides an effective way to handle patients of medical organizations. Psychological bots are able to conduct one-on-one conversations with patients and evaluate each patient's individual requests. The existing e healthcare system is analyzed in this paper and the system involves a novel human -machine interaction and proposes an alternative system. Chatbots are designed and trained in a way for acting and interacting with patients as a human being. The Proposed system is a web application with a bot which can chat in it. A chat interface is provided which allows the users to enter their symptoms manually by this system; and this helps the system to predict the diseases. After predicting the disease, it gives some suggestion which does not involve any medicine as well as also shows the nearby physicians address so that they can consult. The system also provides daily health tips to the users to help them keep their psychological health in check. ${ }^{[54]}$

\section{Agent and Environment}

An AI system is composed of an agent and environment. An agent is special tool in an environment that can help environment to perceive through sensors and acts upon that environment through effectors. Eyes, ears, nose, tongue and skin parallel are the sensory for human agent, and hands, legs, mouth are the other organs that work for effectors. In case of a robotic agent cameras and infrared range finders are use as the sensors, and various motors and actuators for effectors. A software agent to do its programs and actions has encoded bit strings.

In above figure there shows a robot and the world it lives in. The robot is going to take actions that affect the state of the environment and it's going to receive percepts somehow that tell it about what's going on in the environment. If the agent does something that changes the state of the environment, then it perceives some new information about the state of the environment that happen in a loop.

D. PAB as an Agent

There are few types of agent like Goal Based Agents, Simple Reflex Agents, Model Based Reflex Agents, Utility Based Agents etc. PAB is a Model Based Reflex Agents. This type of agent use as a model of the world to choose their actions. They basically maintain an internal state. Model is all about the knowledge about "how the things happen in the environment". Internal State is a representation of unobserved aspects of current state depending on previous history. 


\section{A. Existing System}

\section{TECHNICAL STRUCTURE AND OVERVIEW}

There are a lot of chatbot system but those are working across sales, service and marketing to satisfy customer but there is no such system that working for user psychology. The existing chatbots basically can do automated responses, conversation routing, ability to book meetings, 24/7 operation on your landing pages or applications but can't understand users' psychology. Though there are some bots working across user's physical health but mental health issue was not proposed yet.

B. $\quad$ Proposed System

This proposed system is to create an Artificial Intelligence (AI) based software that can be demonstrated as messaging applications, web applications or mobile applications. A bot that can allow to users to enter their symptoms and the system predict the disease on the base pf data that already given in. Psychological bots are able to conduct one-on-one conversations with patients and evaluate each patient's individual requests. After predicting the disease, it gives some suggestion which does not involve any medicine as well as also shows the nearby physicians address so that they can consult.

\section{System Methodology}

Psychological Assistant Bot is a web based application where user can chat with the bot. The user's input is taken via the device, and this input is perceived by PAB. The input percept then goes for a keyword/pattern match to a knowledge based database where the condition action rules for pattern matching are already given. $\mathrm{PAB}$ is built with supervised learning so the condition-action rule is used for its training. And based on the condition-action rule, the supervised agent PAB takes its decision and response depending on that decision. So the training data set is given while coding and can be updated if required. A figure is given below to demonstrate the system architecture:

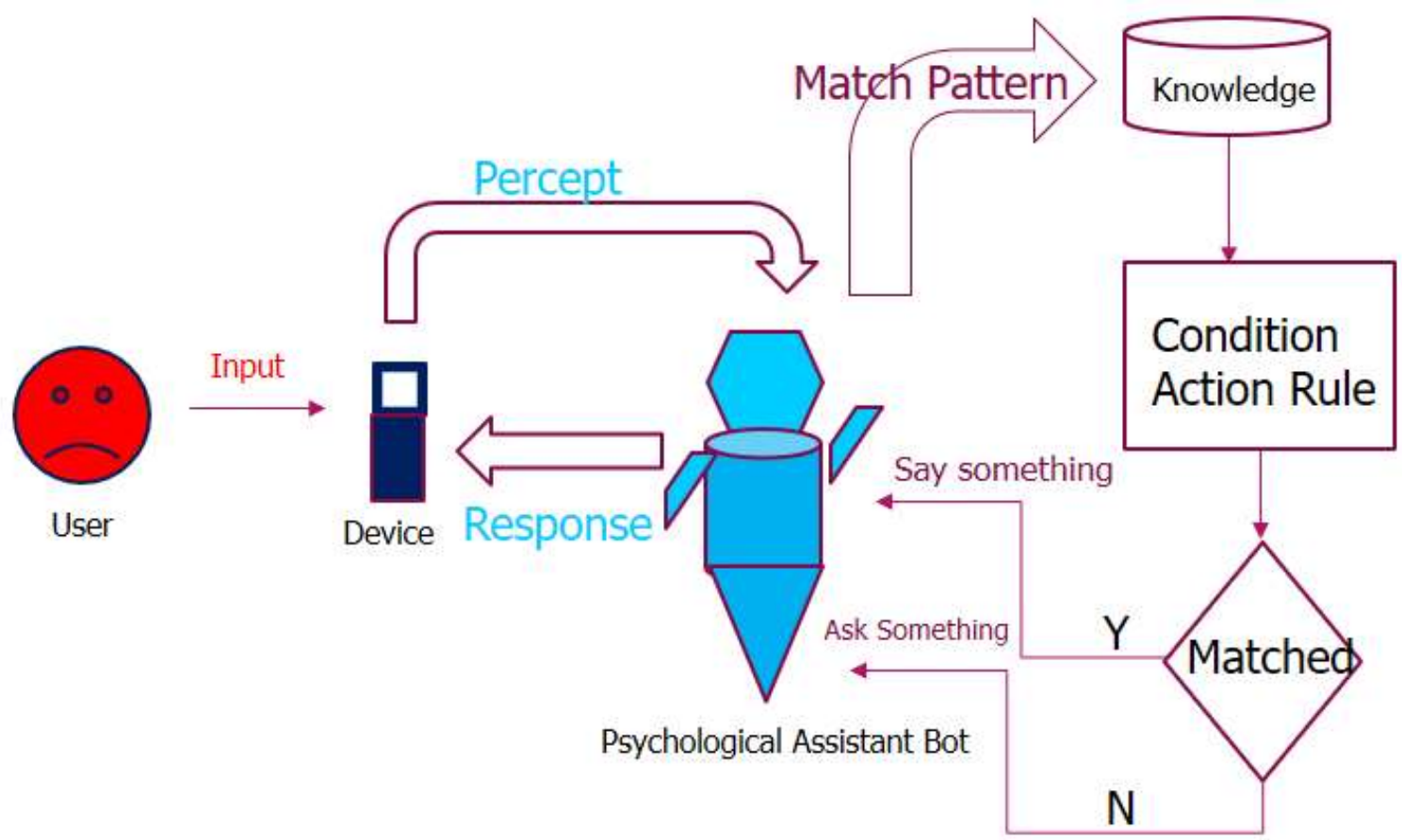

Figure 4: System Methodology of PAB. 


\section{Algorithm}

PAB (INPUT, A, R): INPUT inputs the user's response R and A in the answer given by the chatbot. This algorithm makes the chatbot to mimic human intelligence and convince the user to get over with the disorder while continuing the conversation. Here, DATASET is the training data set that is used for PAB's supervised learning. Fulfillment refers to the

STEP 1: Start Conversation with user

STEP 2: Repeat STEPS 3 and 4 while K=0 TO INPUT== "EXIT"

STEP 3: Ask user question

STEP 4: Input user's response R

a) Repeat while $\mathrm{J}=0$ until Fulfillment $=$ TRUE

b) If R matches with the given DATASET of replies, then ask matched question

i) Repeat STEPS ii and iii for A= SUGGESTION

ii) Ask series of questions and record responses $R$

iii) If SYMPTOM is Matched from given symptoms of DATASET

a) Give a Suggestion

b) Set A= SUGGESTION

iv) Else ask another question

End of inner if-else structure

v) $\mathrm{J}=\mathrm{J}+1$

c) Else print "Sorry cold not understand what you said."

End of outer if-else structure

d) Set $K=K+1$

STEP 5: EXIT

Explanation:

Since we created PAB that is supposed to mimic human interactional behavior, we have tried to create a knowledge based database where some sample dataset is given to teach the chatbot what to match and what to reply based on the user's responses. The statements are given in such a way that when the chatbot replies to the user, the user can have a feeling that he/she is talking to another human being. This learning methodology of PAB follows Supervise Learning Methods. No other built in API was used in PAB. The dataset is designed based on Psychological Aspect's analysis. The symptoms of each mentionable disorders were given in the dataset for teaching PAB. The assistant chat bot looks for the key terms in user's input. Finding out a disorder and give suggestion based on that disorders is controlled by the pattern matching condition-action rules. For example, if the user anywhere in his/her chat mention at least once that she cannot sleep properly, based on that key term the Psychological Assistant Bot would suggest a suggestion like consult a therapist who can suggest you prescribed medicine for better sleeping habit. This process continues until the user wishes to exit by typing exit or a suggestion is given. 


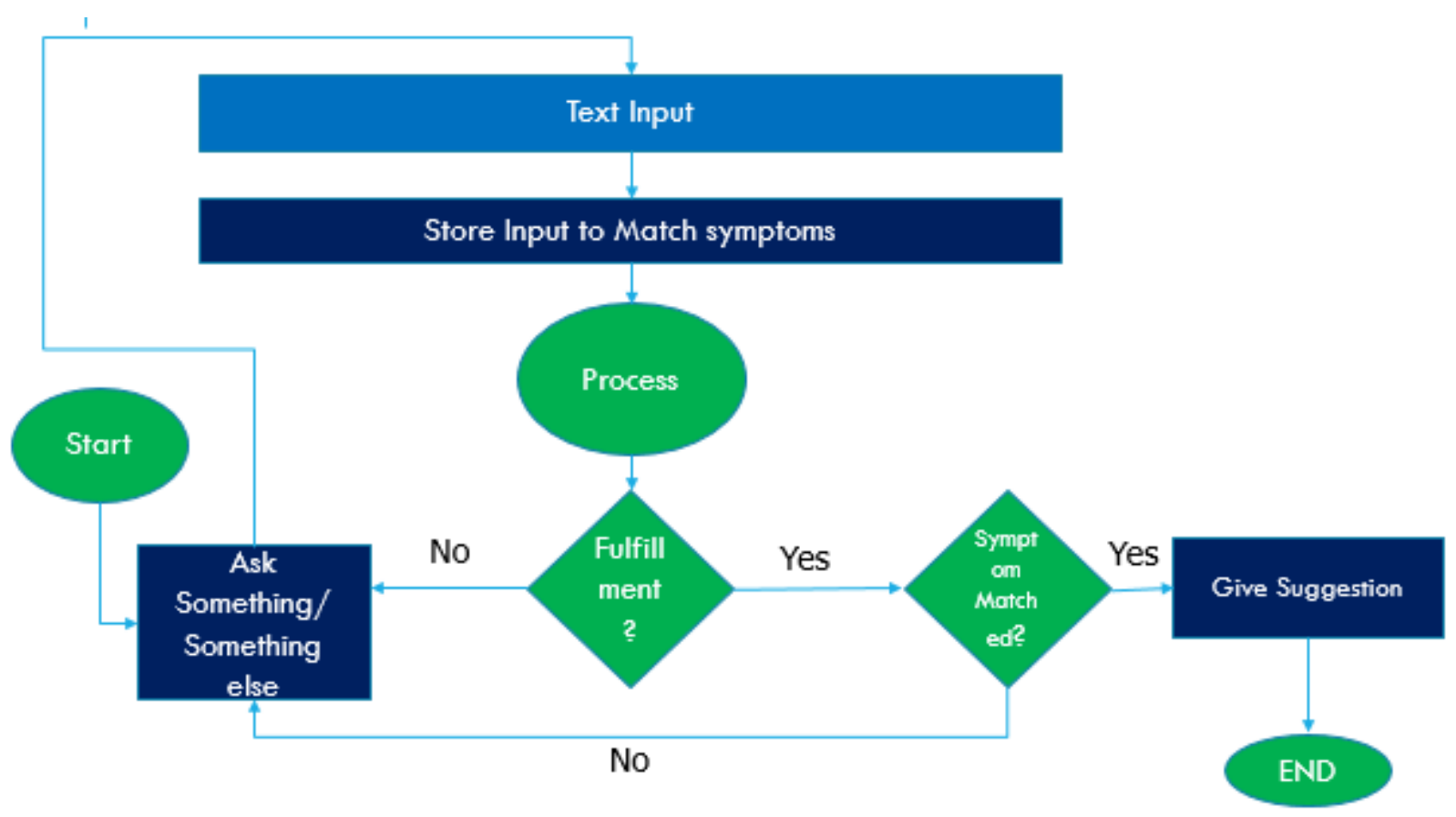

Figure 5: Functionality of $\mathrm{PAB}$ using flow chart.

\section{E. Outcome}

- In the second chapter we have already seen that most people don't want to spend money on psychiatric therapists because for each session the patient has to pay a huge amount of money. Focusing on that point, my Psychological Assistant Bot is very cost efficient. It would be very helpful for the patients who requires Psychological Evaluation.

- Rather than using a built in API, I have tried to implement a training data set for PAB which really helped him to learn and act according to the given knowledge and condition-action rules.

- Since PAB is a web based application it is very easy to access and user friendly.

- Most people do not want to share their problems even with the closest ones because they worry about the invasion of secrecy and privacy but PAB can be really useful for people like introverts, shy or secretive people. So with PAB the privacy is never invaded.

- It provides 24/7-hour service which is very

- PAB cannot be hateful or harmful, so mentally disordered persons would not be triggered by PAB.

\section{F. Comparison with existing system}


In most existing systems, external API is used but for my Psychological Assistant Bot the data set were given. The data set was created based on the psychological aspects. Chatbot like 'ADA', in its response, gives an option-menu. So what the user would input were previously given, but I have added a different method which can be dynamic for users. In PAB, user does not need to answer from a chosen list of answer, but can write whatever the user wants. Which is more dynamic and more realistic as well as human alike than other existing chat bots.

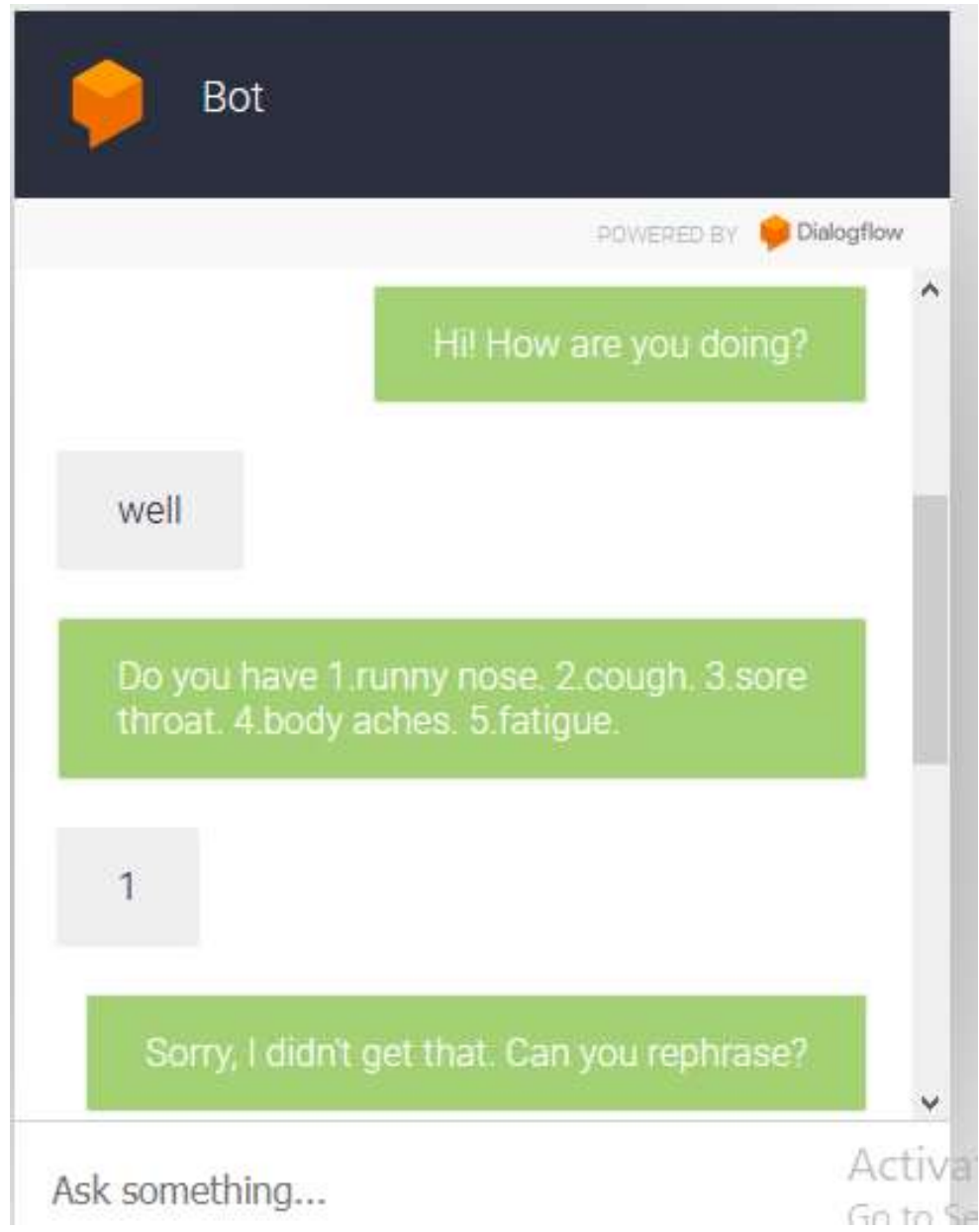

Figure 6: Conversation sample by bot.dialogflow.com 


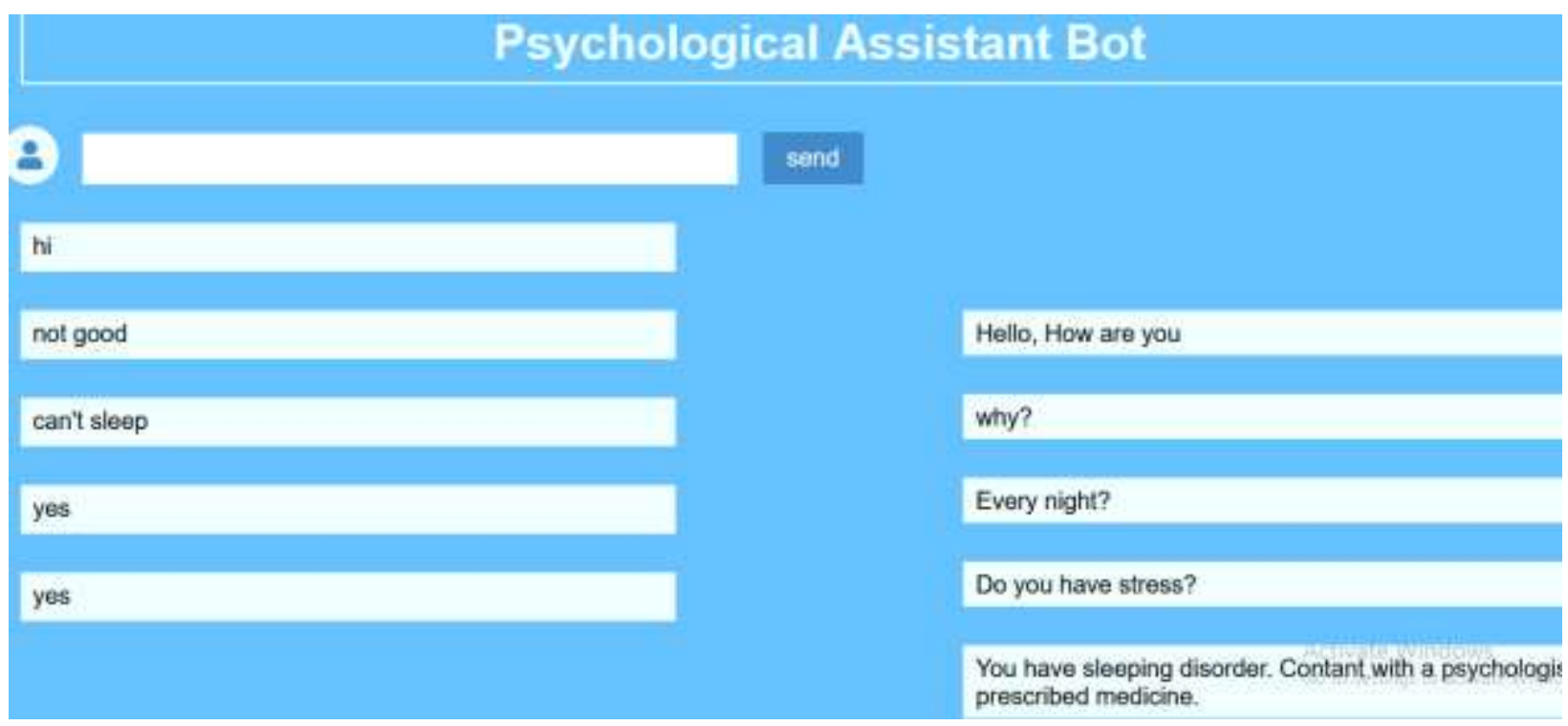

Figure 7: Conversation sample of Psychological Assistant Bot (PAB)

Analysis: In figure 7, the bot has brought the topic about runny nose from just nowhere. The response action depends on the selection of user. Even if the user selects 1, it cannot understand right that moment until he or she can select from the menu and write it in exactly written on the script, it cannot go for key terms. So the pattern matching is not dynamic. But for PAB, I have tried to make the data set variant based on the different psychological aspects. PAB does not send any menu or options to select from there only, so the conversation does not seem selective or objective conversation. $\mathrm{PAB}$ is really trying to mimic human conversation. 


\section{LIMITATIONS AND FUTURE SCOPE}

\section{A. Limitations}

The psychological assistant bot can only be helpful for patients who requires Psychological Evaluation. Other two types of diagnosis cannot be done using PAB. It cannot prescribe medicines to the users. Only text input is available which PAB solely depends only on the responses from user's end. But if for any reason user cannot provide or express how he or she is feeling or cannot use proper words to express the feelings than the suggestion from PAB's end would not be $100 \%$ accurate for that specific user.

\section{B. Future Scope}

Since text input is not enough for $100 \%$ accurate feedback, we can add expression recognition and voice recognition. For better and more accurate performance of PAB, Facial expressions and voices can be an addition to this system. 


\section{CONCLUSION}

The main objective of this proposal was to build an assistant who might help the people either who can't afford the therapists or are on denial of any psychological disorder. Before implementing the system, I have given full focus on the psychological aspects mostly because to create an artificial therapist, the study of Psychological aspects was most important part. Without understanding how a real life Psychological Therapist thinks or decides, it was quite impossible for me to build artificial Psychological Bot. Issues that may affect mental health and provoke people to attempt suicide were highlighted throughout the beginning chapter of this paper.

The proposed algorithm was implemented and the proto type PAB's performance was satisfactory especially compared to other existing bots.

The limitations can be minimized and the future scopes would add more diversity to the bot. 
International Journal of Computer Science and Information Security (IJCSIS), Vol. 18, No. 10, October 2020

\section{REFERENCES}

1. Fernald LD (2008). Psychology: Six perspectives (pp.12-15). Thousand Oaks, CA: Sage Publications.

2. $\wedge$ Hockenbury \& Hockenbury. Psychology. Worth Publishers, 2010.

3. $\hat{\wedge}$ Although psychoanalysis and other forms of depth psychology are most typically associated with the unconscious mind, behaviorists consider such phenomena as classical conditioning and operant conditioning,

while cognitivists explore implicit memory, automaticity, and subliminal messages, all of which are understood either to bypass or to occur outside of conscious effort or attention. Indeed, cognitive-behavioral therapists counsel their clients to become aware of maladaptive thought patterns, the nature of which the clients previously had not been conscious.

4. 1 _ Cacioppo, John (September 2007). "Psychology is a Hub Science". Aps Observer. 20 (8). psychology is a hub discipline - that is, a discipline in which scientific research is cited by scientists in many other fields. For instance, medicine draws from psychology most heavily through neurology and psychiatry, whereas the social sciences draw directly from most of the specialties within psychology. Association for Psychological Science Observer (September 2007)

5. $\_$O'Neil, H.F.; cited in Coon, D.; Mitterer, J.O. (2008). Introduction to psychology: Gateways to mind and behavior (12th ed., pp. 15-16). Stamford, CT: Cengage Learning.

6. $\quad \hat{-}$ "The mission of the APA [American Psychological Association] is to advance the creation, communication and application of psychological knowledge to benefit society and improve people's lives"; APA (2010). About APA. Retrieved 20 October 2010.

7. ^ Jump up to: ${ }^{a}$ "Bangladesh Suicide". worldlifeexpectancy.com. Retrieved 15 November 2012.

8. $\quad \wedge$ "Suicide on the rise in Bangladesh". Dhaka Tribune. 2018-03-27. Retrieved 2019-02-01.

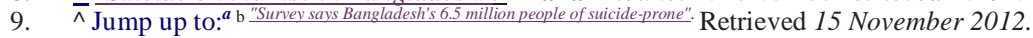

10. ^ Jump up to: ${ }^{a} \mathrm{~b} c$ "10,000 commit suicide a year". The Daily Star. Retrieved 15 November 2012

11. ^ "Bangladeshi women 'at risk of suicide".. BBC News. Retrieved 16 November 2012.

12. $\underline{-}$ Selim, Nasima (2010). "An extraordinary truth? The Addam "suicide" notes from Bangladesh". Mental Health, Religion \& Culture. 13 (3): 223-244. doi: $10.1080 / 13674670903061230$.

13. - "Mymensingh joint suicide defies common sense" (1). BDNews24.com. BDNews24.com. 12 July 2007. Retrieved 30 May 2016.

14. ^ิAhmad, M; Hossain, MZ (14 March 2011). "Hanging as a Method of Suicide: Retrospective Analysis of Postmortem Cases". Journal of Armed Forces Medical College, Bangladesh. 6 (2). doi: 10.3329/jafmc.v6i2.7273.

15. Wikipedia

16. Dhaka Tribune https://www.dhakatribune.com/bangladesh/nation/2020/01/22/mp-s-son-commits-suicide-in-khulna

17. Dhaka Tribune https://www.dhakatribune.com/bangladesh/nation/2020/01/19/boy-commits-suicide-after-not-getting-a-mobile-inkurigram

18. Dhaka Tribune https://www.dhakatribune.com/bangladesh/nation/2019/12/31/2-schoolgirls-commit-suicide-over-jsc-result

19. Daily Jugantar https://www.jugantor.com/capital/270388/

20. Chang B, Gitlin D, Patel R (September 2011). "The depressed patient and suicidal patient in the emergency department: evidencebased management and treatment strategies". Emergency Medicine Practice. 13 (9): 1-23, quiz. 23

4. $\quad \underline{P M I D} 22164363$.

21. University of Manchester Centre for Mental Health and Risk. "The National Confidential Inquiry into Suicide and Homicide by People with Mental Illness"(PDF). Archived from the original (PDF) on 14 July 2012. Retrieved 25 July2012.

22. ^ Stone DM, Simon TR, Fowler KA, Kegler SR, Yuan K, Holland KM, et al. (June 2018). "Vital Signs: Trends in State Suicide Rates - United States, 1999-2016 and Circumstances Contributing to Suicide $=27$ States, 2015". MMWR. Morbidity and Mortality Weekly Report. 67 (22): $617-$ 624. doi:10.15585/mmwr.mm6722a1. PMC 5991813. PMID 29879094.

23. ^A Arsenault-Lapierre G, Kim C, Turecki G (November 2004). "Psychiatric diagnoses in 3275 suicides: a metaanalysis". BMC Psychiatry. 4 (1): 37. doi:10.1186/1471-244X-4-37. PMC 534107. PMID 15527502.

24. Bostwick JM, Pankratz VS (December 2000). "Affective disorders and suicide risk: a reexamination". The American Journal of Psychiatry. 157 (12): 1925-32. doi:10.1176/appi.ajp.157.12.1925. PMID 11097952.

25. Kutcher S, Chehil S (2012). Suicide Risk Management A Manual for Health Professionals (2nd ed.). Chicester: John Wiley \& Sons. pp. 30-33. ISBN $978-1$-119-95311-1.

26. Pompili M, Girardi P, Ruberto A, Tatarelli R (2005). "Suicide in borderline personality disorder: a meta-analysis". Nordic Journal of Psychiatry. 59 (5): 319-24. doi: 10.1080/08039480500320025. PMID 16757458.

27. ^ Bertolote JM, Fleischmann A, De Leo D, Wasserman D (2004). "Psychiatric diagnoses and suicide: revisiting the evidence". Crisis. 25 (4): 147-55. doi:10.1027/0227-5910.25.4.147. PMID 15580849.

28. ^^Angelakis I, Gooding P, Tarrier N, Panagioti M (July 2015). "Suicidality in obsessive compulsive disorder (OCD): a systematic review and meta-analysis". Clinical Psychology Review. 39: 1-

15. doi:10.1016/j.cpr.2015.03.002. PMID 25875222.

29. Zahid, S; Upthegrove, R (July 2017). "Suicidality in Autistic Spectrum Disorders"(PDF). Crisis. 38 (4): 237 246. doi:10.1027/0227-5910/a000458. PMID 28468556.

30. ^ Lieb K, Zanarini MC, Schmahl C, Linehan MM, Bohus M (2004). "Borderline personality disorder". Lancet. 364 (9432): 453-61. doi:10.1016/S0140-6736(04)16770-6. PMID 15288745. Between 40\% and 65\% of individuals who commit suicide meet criteria for a personality disorder, with borderline personality disorder being the most commonly associated.

31. ^ิ van Os J, Kapur S (August 2009). "Schizophrenia" (PDF). Lancet. 374 (9690): 635-45. doi:10.1016/S01406736(09)60995-8. PMID 19700006.

32. ${ }^{\wedge}$ Jump up to: ${ }^{a}{ }^{c}{ }_{\mathrm{d}} \boldsymbol{e}_{\mathrm{f} g}$ Tintinalli, Judith E. (2010). Emergency Medicine: A Comprehensive Study Guide (Emergency Medicine (Tintinalli)). New York: McGraw-Hill Companies. pp. 1940-46. ISBN 978-0-07-148480-0. 
33. ^ Jump up to: ${ }^{a}$ birkis J, Burgess $P$ (December 1998). "Suicide and recency of health care contacts. A systematic review". The British Journal of Psychiatry. 173 (6): 462-74. doi:10.1192/bjp.173.6.462. PMID 9926074.

34. $\wedge$ Luoma JB, Martin CE, Pearson JL (June 2002). "Contact with mental health and primary care providers before suicide: a review of the evidence". The American Journal of Psychiatry. 159 (6): 909-

16. doi:10.1176/appi.ajp.159.6.909. PMC 5072576. PMID 12042175.

35. Sharma T, Guski LS, Freund N, Gøtzsche PC (January 2016). "Suicidality and aggression during antidepressant treatment: systematic review and meta-analyses based on clinical study reports". BMJ. 352.

i65. doi: $10.1136 /$ bmj.i65. PMC 4729837. PMID 26819231.

36. "Suicide Risk and Protective Factors|Suicide|Violence Prevention|Injury Center|CDC". www.cdc.gov. 25 April 2019. Retrieved 17 June 2019.

37. Zalsman G, Hawton K, Wasserman D, van Heeringen K, Arensman E, Sarchiapone M, et al. (July 2016). "Suicide prevention strategies revisited: 10-year systematic review". The Lancet. Psychiatry. 3 (7): 646-59. doi: 10.1016/S22150366(16)30030-X. PMID 27289303. Other approaches that need further investigation include gatekeeper training, education of physicians, and internet and helpline support.

38. Hawton K, Saunders KE, O'Connor RC (June 2012). "Self-harm and suicide in adolescents". Lancet. 379 (9834): 237382. Doi:10.1016/S0140-6736(12)60322-5. PMID 22726518.

39. ^ Jump up to: ${ }^{a}$ "Suicide Risk and Protective Factors|SuicidelViolence Prevention|lniury Center|CDC". www.cdc.gov. 25 April 2019. Retrieved 29 July 2019.

40. Vijayakumar L, Kumar MS, Vijayakumar V (May 2011). "Substance use and suicide". Current Opinion in

Psychiatry. 24 (3): 197-202. doi:10.1097/YCO.0b013e3283459242. PMID 21430536.

41. Simpson G, Tate R (December 2007). "Suicidality in people surviving a traumatic brain injury: prevalence, risk factors and implications for clinical management". Brain Injury. 21 (13-14): 1335-

51. doi:10.1080/02699050701785542. PMID 18066936.

42. Miller M, Azrael D, Barber C (April 2012). "Suicide mortality in the United States: the importance of attending to method in understanding population-level disparities in the burden of suicide". Annual Review of Public Health. 33: 393408. doi: 10.1146/annurev-publhealth-031811-124636. PMID 22224886.

43. Qin P, Agerbo E, Mortensen PB (April 2003). "Suicide risk in relation to socioeconomic, demographic, psychiatric, and familial factors: a national register-based study of all suicides in Denmark, 1981-1997". The American Journal of Psychiatry. 160 (4): $765-$ 72. doi: 10.1176/appi.ajp.160.4.765. PMID 12668367.

44. ^_ Centers for Disease Control Prevention (CDC) (May 2013). "Suicide among adults aged 35-64 years--United States, 1999-2010". MMWR. Morbidity and Mortality Weekly Report. 62 (17): 321-5. PMC 4604925. PMID 23636024.

45. $\wedge$ Gilliland B, James R (2012-05-08). Crisis intervention strategies (7th ed.). Belmont, CA: Brooks/Cole. p. 215. ISBN 978-1-111-18677$\overline{7}$. Archived from the original on 2015-10-03.

46. Turecki G, Brent DA (March 2016). "Suicide and suicidal behaviour". Lancet. 387 (10024): 1227-39. doi:10.1016/S01406736(15)00234-2. PMC 5319859. PMID 26385066.

47. Rozanov V, Carli V (July 2012). "Suicide among war veterans". International Journal of Environmental Research and Public Health. 9 (7): 2504-19. doi:10.3390/ijerph9072504. PMC 3407917. PMID 22851956.

48. ^ Jump up to: ${ }^{a b}$ Brent DA, Melhem N (June 2008). "Familial transmission of suicidal behavior". The Psychiatric Clinics of North America. 31 (2): 157-77. doi:10.1016/j.psc.2008.02.001. PMC 2440417. PMID 18439442.

49. ^ Jump up to: ${ }^{a}$ b $\boldsymbol{c}$ "Suicide Risk and Protective Factors|Suicidel Violence Prevention|lniurv Center|CDC". www.cdc.gov. 25 April 2019. Retrieved 17 June 2019.

50. ^ May, Alexis M.; Klonsky, E. David (2016). "What Distinguishes Suicide Attempters From Suicide Ideators? A Meta-Analysis of Potential Factors". Clinical Psychology: Science and Practice. 23 (1): 5-20. doi:10.1111/cpsp.12136.

51. ^ Klonsky, E. David; May, Alexis M. (2013). "Differentiating Suicide Attempters from Suicide Ideators: A Critical Frontier for Suicidology Research". Suicide and Life-Threatening Behavior. 44 (1): 1-5. doi:10.1111/sltb.12068.

52. ^ Klonsky, E. David; Qiu, Tianyou; Saffer, Boaz Y. (2017). "Recent advances in differentiating suicide attempters from suicide ideators:". Current Opinion in Psychiatry. 30 (1): 15-20. doi:10.1097/YCO.0000000000000294. ISSN 0951-7367

53. A Self-Diagnosis Medical Chatbot Using Artificial Intelligence by Divya, Indumathi, Ishwarya, Priyasankari, Kalpana Devi.

54. Chatbot: A Virtual Medical Assistant by Navida Belgaumwala, (Prof.)Dr. Rajashekarapp

55. https://aichat.com/2019/06/27/data-is-the-key-to-develop-a-truly-conversational-chatbot/

56. https://www.quora.com/What-questions-psychologist-ask-clients

57. https://en.wikipedia.org/wiki/Chatbot

58. A Medical chatbot PDF. 